\title{
An Array with Crossed-Dipoles Elements for Controlling Side Lobes Pattern
}

Jafar Ramadhan Mohammed ( $\square$ jafarram@yahoo.com )

Ninevah University https://orcid.org/0000-0002-8278-6013

Abdulrazaq A. Khmees

Ninevah University

\section{Research Article}

Keywords: Antenna arrays, two crossed dipole elements, asymmetric sidelobe pattern nulling.

Posted Date: June 16th, 2021

DOI: https://doi.org/10.21203/rs.3.rs-570389/v1

License: (9) This work is licensed under a Creative Commons Attribution 4.0 International License. Read Full License 


\title{
An Array with Crossed-Dipoles Elements for Controlling Side Lobes Pattern
}

\author{
Jafar Ramadhan Mohammed and Abdulrazaq A. Khmees \\ College of Electronics Engineering, Ninevah University, Mosul-41002, IRAQ \\ (Phone No. +9647740887829, jafar.mohammed@uoninevah.edu.iq)
}

\begin{abstract}
This paper introduces an array with a new element structure to achieve asymmetric sidelobe pattern nulling which is a much desired feature in many applications such as communication systems, tracking radars, and imaging. The proposed element structure consists of combining two simple wire dipoles in the horizontal and vertical positions to form a crossed dipole element. The array patterns of the horizontal and vertical dipoles alone share some common radiation feature such angular null positions which are exploited to provide sidelobe nulling. By properly scaling the array pattern of the horizontal dipoles and added or subtracted its array pattern from that of the vertical dipoles, a new array pattern corresponds to the crossed dipoles elements with controlled sidelobes pattern can be obtained. The scaling factor selects which sidelobes to be cancelled. The method is equally applied to the uniformly and nununiformly excited arrays. The proposed idea is verified by simulating an array with 10 half wavelength crossed dipoles using CST microwave studio.
\end{abstract}

Index Terms - Antenna arrays, two crossed dipole elements, asymmetric sidelobe pattern nulling.

\section{INTRODUCTION}

Currently antenna arrays play a very important role in enhancing the performances of many modern wireless communication systems through configuring their radiation patterns to be maximum at some desired directions and minimum at some other undesired directions. The sidelobe pattern nulling of antenna arrays can easily block the undesired signals at the antenna end. Thus, low sidelobes either on one side or both sides of the main beam and pattern nulling which they are depend on the excitation currents of the antennas are necessary for these applications. Many numerical algorithms have been proposed in the literature for optimizing the excitation currents to get the desired array patterns, for example see [1-6]. However, these optimization methods were generally difficult and complex. Thus, the authors in [7-9] investigated simpler methods for obtaining the required array patterns where they suggested formulating an appropriate auxiliary pattern from reusing two or more side elements whose sidelobes are 
similar to that of the complete array pattern. Then, a required pattern nulling was obtained by subtracting the auxiliary pattern form that of the complete array pattern. These methods were simple since only two or a few number of reused array elements was made re-adjustable. In [10], scanned sub-arrays were used to generate sum and difference patterns, while in [11-12] a genetic algorithm was used to find and optimize the most active elements that could effectively contribute to generate the required nulls. On the other hand, the authors in [13-14] suggested exploring common current excitations to simplify the array feeding network while generating the required array patterns.

In all of the aforementioned methods, the type of the array elements was not investigated. The aim of this paper is mainly to present an efficient structure of the radiation elements that can produce an array with required sidelobe pattern nulling. This can be achieved, by considering two dipole elements and putting them in a crossed form configuration such that their corresponding array patterns can be added or subtracted to produce a new pattern with required sidelobe nulling .

\section{PRINCIPLES OF THE TECHNIQUE}

\section{A. Conventional Array with Horizontal or Vertical Dipole Elements}

Consider $N$ dipole elements that are arranged linearly along the z-axis and positioned either horizontally toward the $\mathrm{x}$-axis or vertically toward z-axis, as shown in Fig.1. The separation distance between any two adjacent dipoles is set to $d=\lambda / 2$. The element excitation amplitude of nth element is denoted by $a_{n}$ and its progressive phase is $\beta$. Thus, the array factor of such array in the far-field observations can be written as follows [15]:
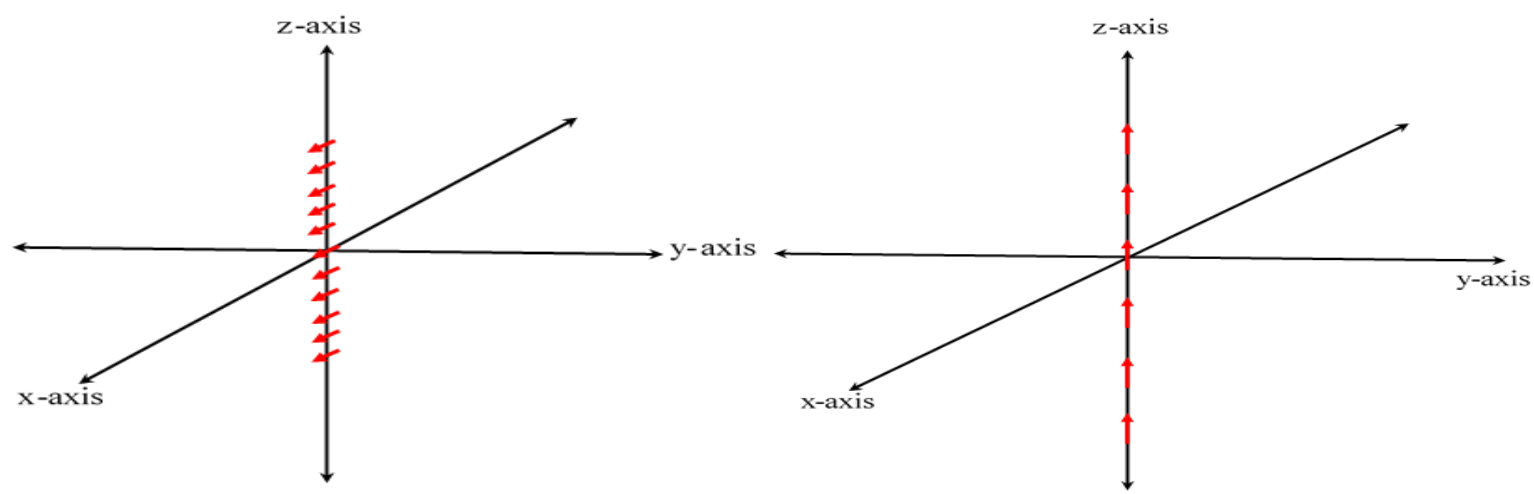

Fig.1 An array with $N$ dipole elements positioned horizontally (left) or vertically (right) along the $z$-axis. 
$\operatorname{AF}(\theta)=\sum_{n=1}^{N} a_{n} e^{j\left[(n-1) \psi_{z}\right]}$

where $a_{n}$ is the amplitude element excitation coefficients, $\psi=k d_{z} \cos \theta+\beta, d_{z}$ is the spacing between elements along the $\mathrm{z}$-axis $\mathrm{k}=2 \pi / \lambda$ and $\lambda$ is the wavelength in free space. Note that the array factors of these two configurations are same, only the element patters differ. Thus, the overall array pattern (AP) for these two configurations can be obtained by multiplying the element pattern by the array factor as follows

$$
\begin{aligned}
& \operatorname{AP}(\theta)_{\text {Horizental }}=\underbrace{\sum_{\text {Array Factor }}^{\cos \theta}}_{\text {Element Pattern }} \\
& \operatorname{AP}(\theta)_{\text {Vertical }}=\underbrace{\sin _{n=1}^{\mathrm{N}} \mathrm{a}_{\mathrm{n}} \mathrm{e}^{\mathrm{j}\left[(\mathrm{n}-1) \mathrm{kd}_{\mathrm{z}} \cos \theta\right]}}_{\text {Element Pattern }} \\
& \underbrace{\sum_{\mathrm{n}=1}^{\mathrm{N}} \mathrm{a}_{\mathrm{n}} \mathrm{e}^{\mathrm{j}\left[(\mathrm{n}-1) \mathrm{kd}_{\mathrm{z}} \cos \theta\right]}}_{\text {Array Factor }}
\end{aligned}
$$

The above two array patterns are plotted for $\mathrm{N}=20$ dipoles as shown in Fig.2.
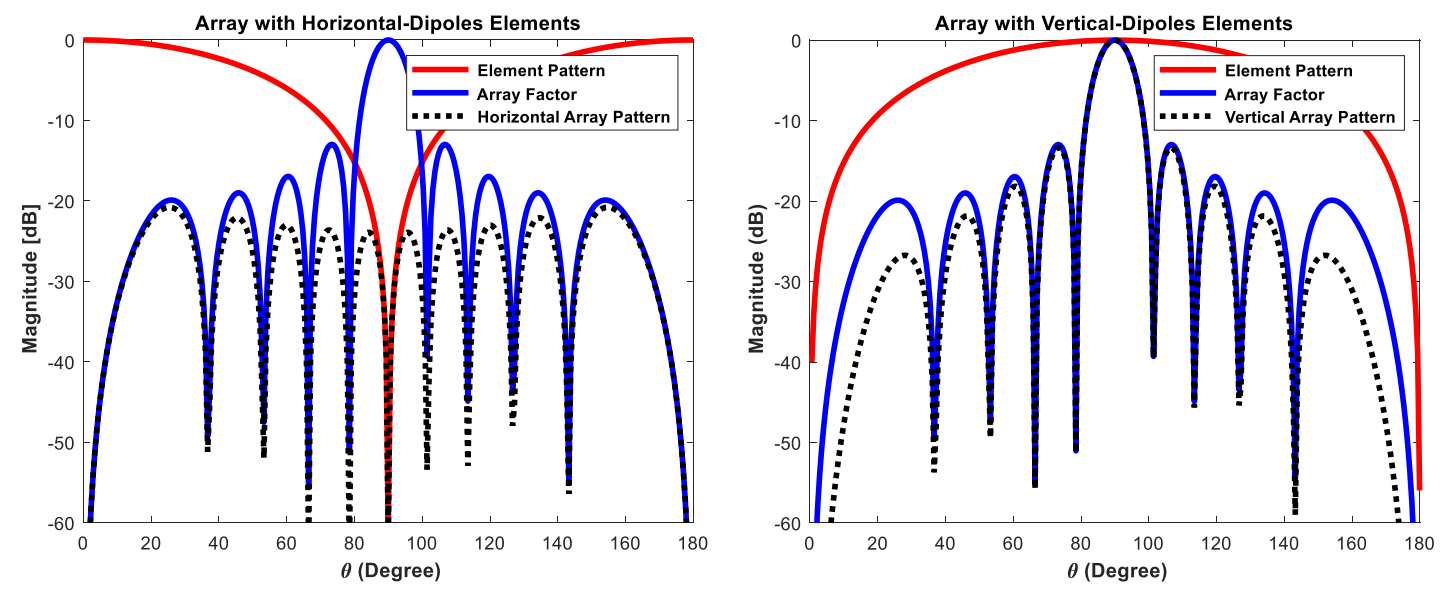

Fig.2 Array Patterns For $N=20$ dipoles positioned horizontally (left) or vertically (right) along the $z$-axis.

From figure 2, it can be seen that the resultant array pattern of the horizontal dipoles is in the form of sidelobes in which its nulls are exactly coincident with those of the resultant vertical array pattern. By combining these two antenna arrays with their resultant patterns of the vertical and horizontal array dipoles, one can get a new array with its elements as a two crossed dipoles.

\section{B. An Array with Two Crossed Dipole Elements}

In this section, the array elements are chosen such that the horizontal and vertical dipoles are combined to form a cross dipole for each array element. Then, the overall array pattern of the 
combined arrays is the superposition of the horizontal and vertical array patterns. As mentioned the nulls of the array patterns of the horizontal and vertical dipoles are exactly coincidence. Thus, we need only to properly scale the magnitudes of the horizontal array pattern. Note that the horizontal and vertical array patterns are in-phase in one side and they are anti-phase in another side of the array pattern. Therefore, a great reduction in the sidelobe pattern can be obtained in one side and an increase in the sidelobe level in the other side. In other words, asymmetric sidelobes with the overall array pattern can be obtained. Moreover, depending on the value of scaling factor $(K)$, a deep wide null can be also introduced in the overall array pattern. This is explained in the flowing equation:-

$$
\mathrm{AP}(\theta)_{\text {Crossed }}=\mathrm{K} \underbrace{\cos (\theta) \sum_{n=1}^{\mathrm{N}} \mathrm{a}_{\mathrm{n}} \mathrm{e}^{\mathrm{j}\left[(\mathrm{n}-1) \mathrm{kd}_{\mathrm{z}} \cos \theta\right]}}_{\text {Horizontal Array Pattern }}+\underbrace{\sin (\theta) \sum_{\mathrm{n}=1}^{\mathrm{N}} \mathrm{a}_{\mathrm{n}} \mathrm{e}^{\mathrm{j}\left[(\mathrm{n}-1) \mathrm{kd}_{\mathrm{z}} \cos \theta\right]}}_{\text {Vertical Array Pattern }}
$$

By applying the above equation for $\mathrm{K}=1$ and $\mathrm{N}=20$, an overall array pattern for the two crossed dipole elements can be obtained as shown in Fig.3.
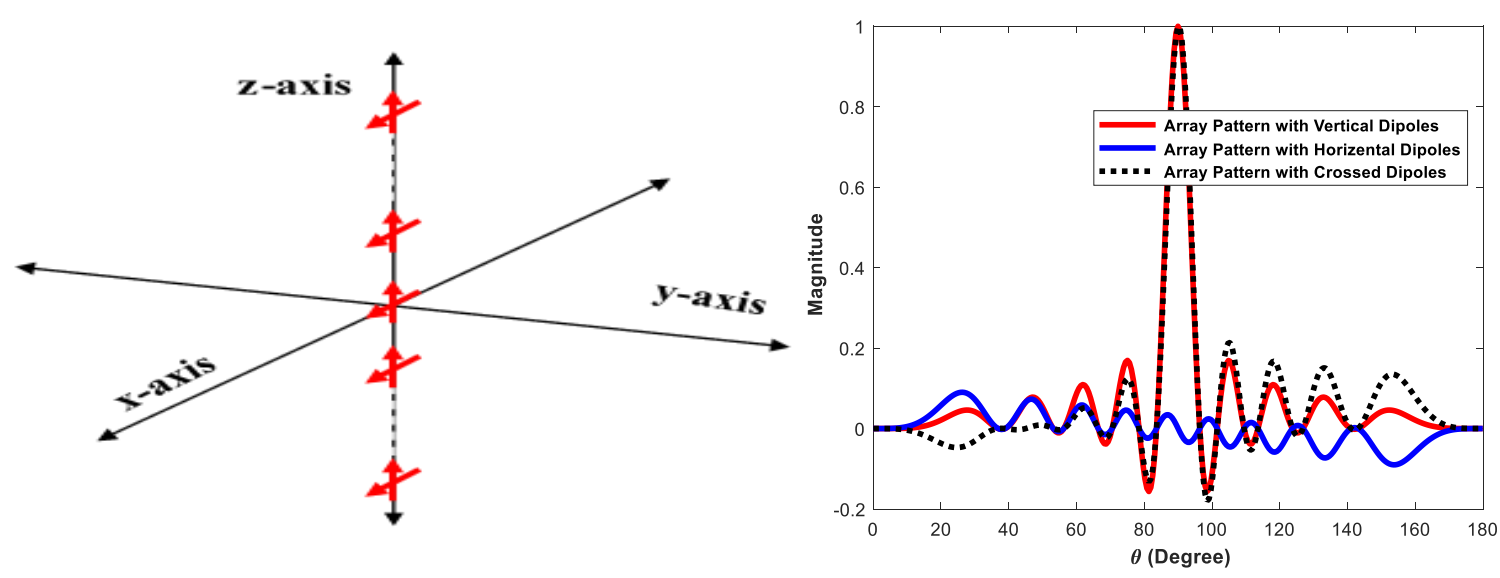

Fig.3 Structure of the proposed array (left), and its Overall Array Pattern for $K=1$ and $N=20$.

\section{SIMULATION RESULTS}

To demonstrate the possibilities of the proposed method in generating the required pattern nulling, three various cases are presented where the first case is related to the uniformly excited arrays, while the other two cases are related to the non-uniformly excited arrays such as Dolph, and Taylor. In all cases, an array with 10 crossed-dipole elements along the z-axis is considered. Moreover, the interelement spacing between any two successive crossed-dipole elements is chosen to be $0.5 \lambda$. For Dolph excited arrays, the desired SLL was set to $-26 \mathrm{~dB}$, while for Taylor excited arrays they are set to SLL $=-20 \mathrm{~dB}$, and nbar $=4$. The scaling factor was variable for each case to get best match in the sidelobe regions of the horizontal and vertical array patterns. 
In the first case, the scaling factor was set to $\mathrm{K}=1$ such that the third sidelobe can be cancelled. The array patterns according to (4) were obtained as shown in Fig. 4. Further, table I shows the performance measures in terms of directivity, both peak and average sidelobes, and the beamwidths of the tested arrays. It can be seen that the third sidelobes on the left side on the main beam in the uniform, Taylor, and Dolph array patterns with crossed-dipole elements are cancelled. Moreover, many of the other sidelobes on the left side were reduced down with compared to that of the vertical dipole array pattern.

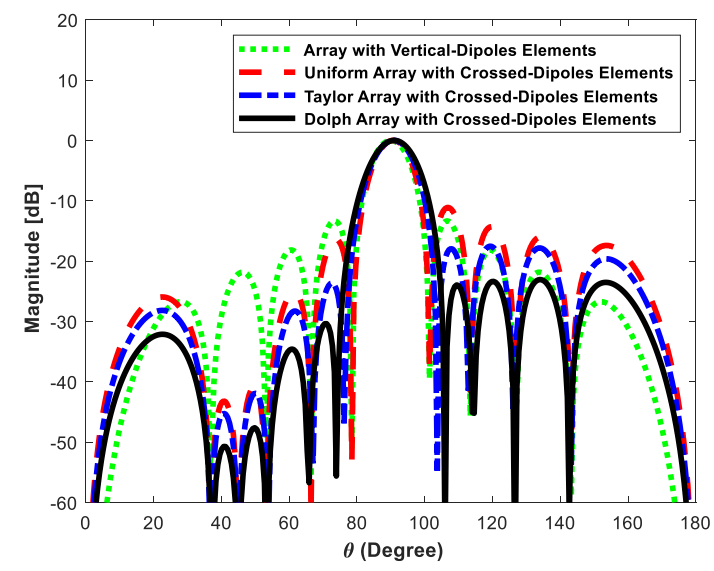

Fig.4 Array Patterns for $K=1$.

Table I Performance Measures for $\mathrm{K}=1$

\begin{tabular}{|c|c|c|c|c|c|c|}
\hline The Method & $\begin{array}{l}\text { Directivity } \\
\text { [dB] }\end{array}$ & $\begin{array}{c}\text { Peak } \\
\text { SLL-left } \\
\text { [dB] }\end{array}$ & $\begin{array}{c}\text { Peak } \\
\text { SLL-right } \\
{[\text { dB] }}\end{array}$ & $\begin{array}{l}\text { FNBW } \\
\text { [Deg.] }\end{array}$ & $\begin{array}{c}\text { HPBW } \\
\text { [Deg.] }\end{array}$ & $\begin{array}{l}\text { Average- } \\
\text { SLL } \\
\text { [dB] }\end{array}$ \\
\hline $\begin{array}{l}\text { Uniformly Excited } \\
\text { Array with Vertical- } \\
\text { Dipole Elements }\end{array}$ & 10.13 & -13.3 & -13.3 & 22.8 & 10 & -13.07 \\
\hline $\begin{array}{l}\text { Uniformly Excited } \\
\text { Array with Crossed- } \\
\text { Dipole Elements }\end{array}$ & 10.06 & -16.4 & -11.1 & 22.8 & 11.4 & -12.1 \\
\hline $\begin{array}{l}\text { Dolph Excited Array } \\
\text { with Crossed-Dipole } \\
\text { Elements }\end{array}$ & 9.59 & -30.4 & -23.8 & 32 & 13.8 & -10.47 \\
\hline $\begin{array}{l}\text { Taylor Excited Array } \\
\text { with Crossed-Dipole } \\
\text { Elements }\end{array}$ & 9.89 & -32.7 & -18 & 27.4 & 12.6 & -10.7 \\
\hline
\end{tabular}

In the second case, the scaling factor was set to $\mathrm{K}=1.767$ and the resultants array patterns are as shown in Fig. 5 and their performance measures as shown in Table II. It can be seen that the second sidelobes are cancelled. Moreover, many of the other sidelobes on the left side were reduced down with compared to that of the vertical dipole array pattern. 


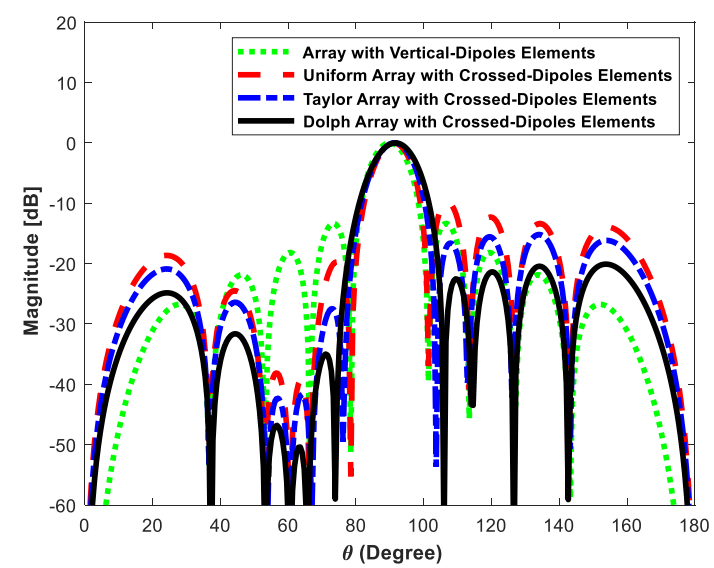

Fig.5 Array Patterns for $K=1.767$.

Table II Performance Measures for K=1.767

\begin{tabular}{|c|c|c|c|c|c|c|}
\hline The Method & $\begin{array}{c}\text { Directivity } \\
\text { [dB] }\end{array}$ & $\begin{array}{c}\text { Peak } \\
\text { SLL-left } \\
\text { [dB] }\end{array}$ & $\begin{array}{l}\text { Peak } \\
\text { SLL-right } \\
\text { [dB] }\end{array}$ & $\begin{array}{c}\text { FNBW } \\
\text { [Deg.] }\end{array}$ & $\begin{array}{c}\text { HPBW } \\
\text { [Deg.] }\end{array}$ & $\begin{array}{l}\text { Average- } \\
\text { SLL } \\
\text { [dB] }\end{array}$ \\
\hline $\begin{array}{l}\text { Uniformly Excited } \\
\text { Array with Vertical- } \\
\text { Dipole Elements }\end{array}$ & 10.13 & -13.3 & -13.3 & 22.8 & 10 & -13.07 \\
\hline $\begin{array}{l}\text { Uniformly Excited } \\
\text { Array with Crossed- } \\
\text { Dipole Elements }\end{array}$ & 9.91 & -19.7 & -9.8 & 22.8 & 11.8 & -11.58 \\
\hline $\begin{array}{l}\text { Dolph Excited Array } \\
\text { with Crossed-Dipole } \\
\text { Elements }\end{array}$ & 9.64 & -27.45 & -22.5 & 32 & 15 & -10.13 \\
\hline $\begin{array}{l}\text { Taylor Excited Array } \\
\text { with Crossed-Dipole } \\
\text { Elements }\end{array}$ & 9.86 & -35 & -16.6 & 27.4 & 13.8 & -10.8 \\
\hline
\end{tabular}

In the third case, the scaling factor was chosen, $K=3.3$, such that the first sidelobe in the proposed array can be cancelled. The resultants array patterns are as shown in Fig. 6 and their performance measures as shown in Table III.

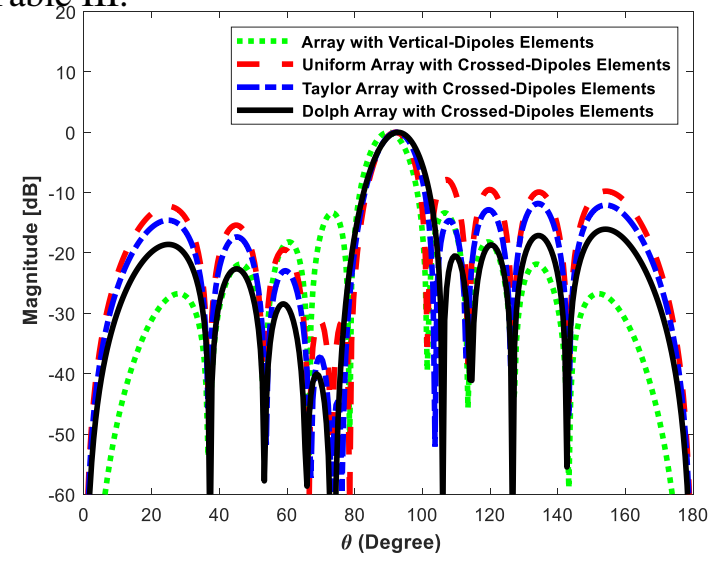

Fig.6 Array Patterns for $K=3.3$. 
Table III Performance Measures for $\mathrm{K}=3.3$

\begin{tabular}{lcccccc}
\multicolumn{1}{c}{ The Method } & $\begin{array}{c}\text { Directivity } \\
{[\mathrm{dB}]}\end{array}$ & $\begin{array}{c}\text { Peak } \\
\text { SLL-left } \\
{[\mathrm{dB}]}\end{array}$ & $\begin{array}{c}\text { PLL-right } \\
\text { SdB] }\end{array}$ & $\begin{array}{c}\text { FNBW } \\
{[\mathrm{Deg} .]}\end{array}$ & $\begin{array}{c}\text { HPBW } \\
{[\text { Deg.] }}\end{array}$ & $\begin{array}{c}\text { Average- } \\
\text { SLL [dB] }\end{array}$ \\
$\begin{array}{l}\text { Uniformly Excited } \\
\begin{array}{l}\text { Array with Vertical- } \\
\text { Dipole Elements }\end{array}\end{array}$ & 10.13 & -13.3 & -13.3 & 22.8 & 10 & -13.07 \\
$\begin{array}{l}\text { Uniformly Excited } \\
\text { Array with Crossed- } \\
\text { Dipole Elements } \\
\text { Dolph Excited Array } \\
\text { with Crossed-Dipole }\end{array}$ & 9.45 & -31.3 & -7.8 & 22.8 & 13 & -10.94 \\
$\begin{array}{l}\text { Elements } \\
\text { Taylor Excited Array } \\
\text { with Crossed-Dipole }\end{array}$ & 9.77 & -40 & -20.5 & 32 & 11.5 & -9.66 \\
Elements & 9.74 & -37.3 & -14.6 & 27.4 & 10.5 & -10.4 \\
\hline
\end{tabular}

Finally, in order to consider the effects of element type, feeding position, mutual coupling, scattering and many other effects, full simulation using CST is done for 10 crossed-dipoles elements array with discrete ports as shown in Fig.7(left). The return loss curve has been shown in this figure (see Fig.7 right). Table IV shows the details of design parameters of the proposed crossed-dipoles elements.

Table IV Design Parameters

Resonant Frequency (fr). $\quad 2.4 \mathrm{GHz}$.

Wavelength $(\lambda)$.

$124.91 \mathrm{~mm}$.

Length of the dipole (L). $\quad \mathrm{L}=\lambda / 2=62.455 \mathrm{~mm}$ (Copper annealed).

The feeding gap $(\mathrm{G})$.

$\mathrm{G}=\mathrm{L} / 100=0.6245 \mathrm{~mm}$ (Air).

Radius of the dipole $(\mathrm{R}) \quad \mathrm{R}=\lambda / 1000=0.1249 \mathrm{~mm}$

Impedance

73(Ohm)
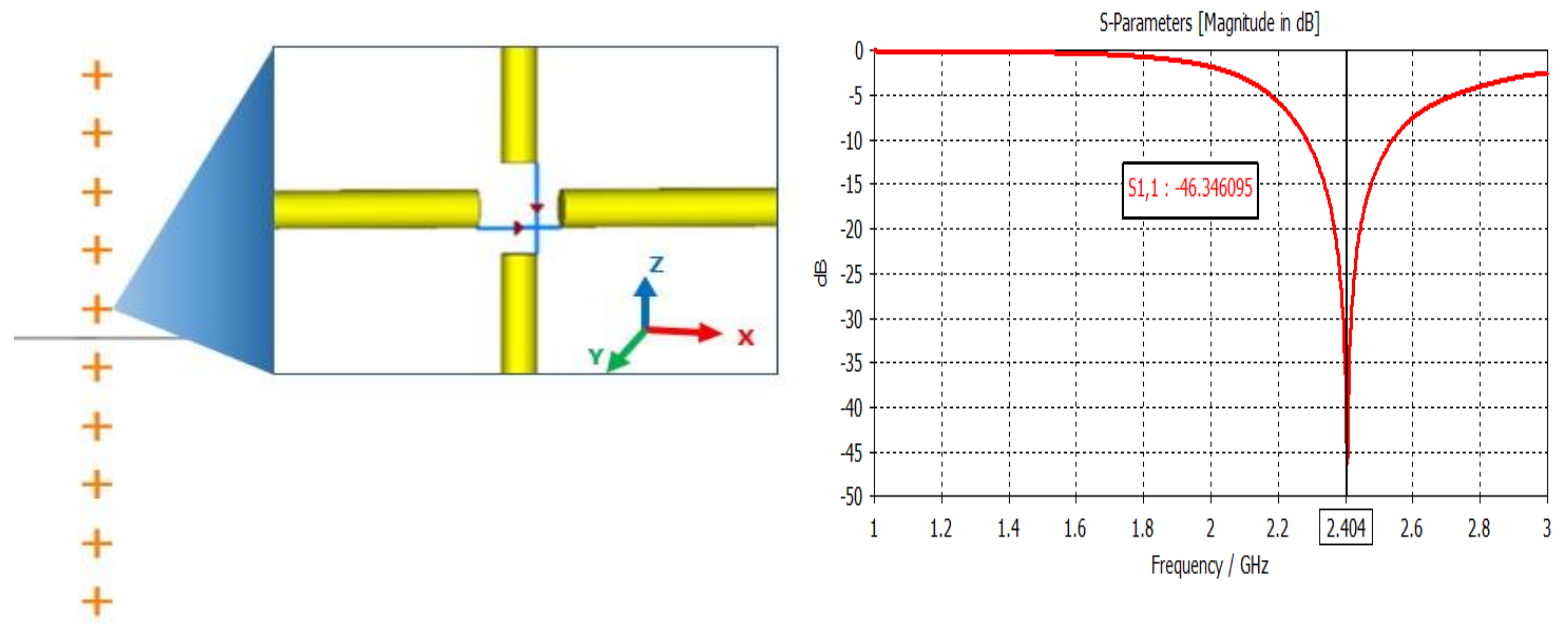

Fig.7 Structure of the Designed Array (left) and its S Parameter at F=2.4 GHz. 
Fig. 8 shows the results of the designed array. The CST results are found satisfactory and in good agreement with the theoretical Matlab findings. The return loss value was at $-46.3 \mathrm{~dB}$ at frequency $2.404 \mathrm{GHz}$ and the bandwidth was found to be around $261 \mathrm{MHz}$, which is suitable for many wireless applications.

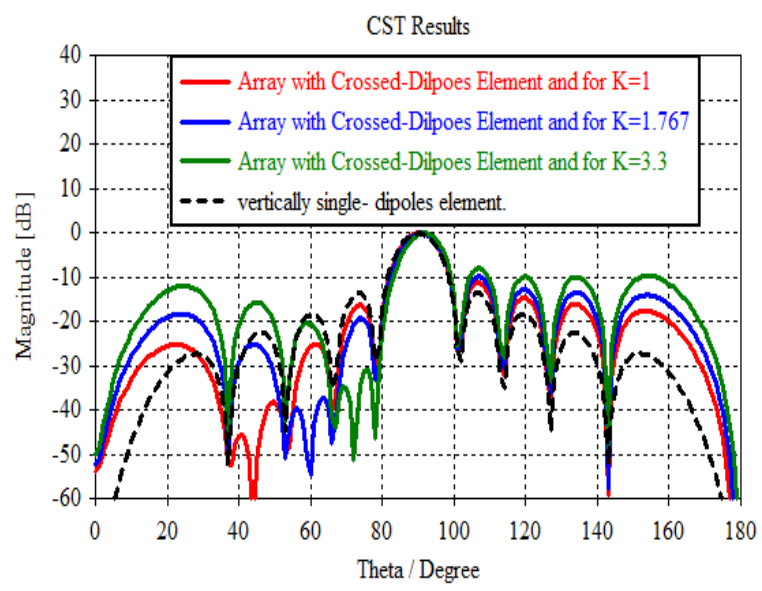

Fig.8 CST Results for Various Values of Scaling Factor, $K$.

\section{CONCLUSIONS}

From the presented results, it can be found that the proposed array is capable to provide a required pattern with controlled nulls that depend on the selecting value of the scaling factor. The method is equally applicable to both uniformly and non-uniformly excited arrays. For all considered arrays, the differences between sidelobe levels on both sides of the main beam were more than $-20 \mathrm{~dB}$. Moreover, the directivity of the proposed array was found to be slightly reduced with compared to that of the conventional array with single-dipole elements. Finally, an array with the proposed crossed-dipole elements was designed and simulated using CST microwave studio and its results were compared to the theoretical Matlab findings, which confidently validated the presented idea.

The proposed array can be further extended to include the circular polarization.

\section{REFERENCES}

[1] K. Guney and M. Onay, "AMPLITUDE-ONLY PATTERN NULLING OF LINEAR ANTENNA ARRAYS WITH THE USE OF BEES ALGORITHM," Prog. Electromagn. Res., vol. 70, no. 5, pp. 21-36, Sep. 2007, doi: 10.2528/PIER07011204.

[2] K. Güney and A. Akdağli, "Null steering of linear antenna arrays using a modified tabu search algorithm," J. Electromagn. Waves Appl., vol. 15, no. 7, pp. 915-916, Jan. 2001, doi: $10.1163 / 156939301 X 00878$. 
[3] S. Banerjee and D. Mandal, "Array pattern optimization for a steerable circular isotropic antenna array using the firefly algorithm," Journal of Computational Electronics, vol. 16, issue 3, pp. 952-976, September 2017.

[4] Mohammed, J.R., "An Optimum Side Lobe Reduction Method with Weight Perturbation", Journal of Computational Electronics, US Springer, vol.18, no.2, pp.705-711, June 2019.

[5] N. Karaboga, K. Güney, and A. Akdagli, "Null steering of linear antenna arrays with use of modified touring ant colony optimization algorithm," Int. J. RF Microw. Comput. Eng., vol. 12, no. 4, pp. 375-383, Jul. 2002, doi: 10.1002/mmce.10034.

[6] S. Kwak, J. Chun, D. Park, Y. K. Ko, and B. L. Cho, "Asymmetric sum and difference beam pattern synthesis with a common weight vector," IEEE Antennas Wirel. Propag. Lett., vol. 15, pp. 1622-1625, 2016, doi: 10.1109/LAWP.2016.2519530.

[7] Khalil H. Sayidmarie and Jafar R.Mohammed, "Design of a Linear Array with Asymmetric Low Side Lobes," AL- Rafidain Engineering, vol. 12. pp. 1-9, 2004.

[8] Mohammed, J. R., "Phased Array Antenna with Ultra-Low Sidelobes" Electronics Letters, vol. 49, issue 17, pp. 1055-1056, August 2013

[9] J. R. Mohammed and K. H. Sayidmarie, "Synthesizing Asymmetric Side Lobe Pattern with Steered Nulling in Nonuniformly Excited Linear Arrays by Controlling Edge Elements," Int. J. Antennas Propag., vol. 2017, pp. 1-7, 2017, doi: 10.1155/2017/9293031.

[10] J. R. Mohammed, "Synthesizing Uniform Sum and Difference Patterns by Controlling Steer Angle and using Sub-Arrays," Global Journal of Researches in Engineering: F Electrical and Electronics Engineering, vol. 17, no. 7. 2017.

[11] Mohammed, J.R.," Optimal Null Steering Method in Uniformly Excited Equally Spaced Linear Array by Optimizing Two Edge Elements", Electronics Letters, vol. 53, issue 13, pp. 835-837, June 2017

[12] J. R. Mohammed, "Element Selection for Optimized Multiwide Nulls in Almost Uniformly Excited Arrays," IEEE Antennas Wirel. Propag. Lett., vol. 17, no. 4, pp. 629-632, Apr. 2018, doi: 10.1109/LAWP.2018.2807371.

[13] M. Alvarez-Folgueiras, J. Rodriguez-Gonzales, and F. Ares-Pena, "Synthesizing Taylor and Bayliss linear distributions with common aperture tail," Electron. Lett., vol. 45, no. 11, pp. 18 19, 2009.

[14] A. F. Morabito and P. Rocca, "Optimal synthesis of sum and difference patterns with arbitrary sidelobes subject to common excitations constraints," IEEE Antennas Wireless Propag. Lett., vol. 9, pp. 623-626, 2010.

[15] C. A. Balanis, Antenna Theory Analysis And Design, Fourth Edi. Hoboken, New Jersey: John Wiley \& Sons, Inc., 2016. 